\title{
Effect of 8-Week Aerobic, Strength and Concurrent Training on Circulating Apelin in Morphine-Dependent Rats
}

\author{
Ebrahim Zarrinkalam (MSc) \\ Department of Exercise Physiology, \\ Faculty of Physical Education and \\ Sport Sciences, Bu-Ali Sina \\ University, Hamedan, Iran \\ Ali Heidarianpour (PhD) \\ Department of Exercise Physiology, \\ Faculty of Physical Education and \\ Sport Sciences, Bu-Ali Sina \\ University, Hamedan, Iran \\ Corresponding author: Ali \\ Heidarianpour \\ Email: zarrinkalam@gmail.com \\ Tel: +989183160986 \\ Address: Department of Exercise \\ Physiology, Faculty of Physical \\ Education and Sport Sciences, Bu-Ali \\ Sina University, Hamedan, Iran
}

Received : 15 Feb 2016

Revised: 02 Apr 2016

Accepted: 05 Apr 2016

\section{ABSTRACT}

Background and Objectives: Previous studies have shown that morphine dependence leads to myocardial dysfunction. In addition, apelin plays a protective role in cardiac function. The purpose of this study was to evaluate effects of morphine dependence and three models of exercise training on serum apelin level of dependent and healthy rats.

Methods: Ten healthy and 40 morphine-dependent rats were used in this study. The morphine-dependent rats were divided into four equal groups of control addicts, endurance training, strength training and concurrent training. The training exercises were carried out for eight weeks, five days a week. Serum apelin level was measured by ELISA, 72 hours after the last training session.

Results: Statistical analysis demonstrated that apelin level increased significantly in morphine-dependent rats compared to healthy controls. On the other hand, endurance and concurrent training significantly increased serum apelin level in morphine-dependent rats compared to control addicts, but strength training had not effect on serum apelin level in morphine-dependent rats.

Conclusion: Endurance and concurrent training may have cardioprotective effects on morphine-dependent rats by increasing serum apelin levels. Therefore, such training activities could be recommended to morphine-dependent patients to prevent cardiac disorders.

Keywords: Apelin, Morphine, Exercise. 


\section{INTRODUCTION}

Addiction to morphine is a serious global health problem. Although it has some known beneficial effects, its consumption is limited to the treatment of chronic pain due to high risk of tolerance, dependence and subsequently addiction (1). Previous studies have shown that morphine-dependent patients have left ventricular systolic dysfunction and reduced cardiac function (2). In this regard, Mesripour et al. showed that morphine dependence induces ventricular remodeling and increases oxidative stress (3). On the other hand, it has been proven that exercise has cardioprotective activity against damages caused by myocardial ischemia reperfusion, and helps improve left ventricular function through development of sarcoplasmic network, angiogenesis and decreased cardiac arrhythmias.

Molecular mechanism of the cardioprotective effects of exercise on heart of morphinedependent patients is unknown. Apelin is a peptide involved in the regulation of cardiovascular function. This endogenous ligand for the G-protein-coupled receptor APJ, exerts strong inotropic activity and increases coronary blood flow by vascular dilation (4). There are at least four bioactive apelin isoforms including apelin-12, $-13,-17$, and 36. Recently, apelin has been detected in several tissues such as white adipose tissue, kidney, heart, and blood vessel (5). Clinical evidence suggests that plasma apelin levels are generally lower in patients with cardiovascular disease (6). In response to pathological stress, apelin-APJ axis regulates myocardial remodeling, cardiac contractility (7) and cardiac function (8). Loss of apelin impairs ischemia/reperfusion remodeling and exacerbates myocardial ischemia/reperfusion injury both ex vivo and in vivo (9). When administered 10 minutes before cardiac ischemia, morphine $(0.3 \mathrm{mg} / \mathrm{kg})$ induced preconditioning of the heart to reduce infarct size after coronary artery ligation (10). Development of age-related progressive cardiac dysfunction in apelin-deficient mice can be prevented by apelin infusion (11), which suggest the important role of this peptide in maintaining cardiac performance. Previous studies demonstrated that surviving adult $\mathrm{Apj}^{-1-}$ mice have cardiovascular dysfunction. Noninvasive imagining studies and isolated cardiomyocyte studies have shown that this is attributable, at least in part, to a primary defect in cardiac contraction (12). A study has suggested that apelin in tissue and blood could have a tonic effect on contractile function in adult mice (13). However, previous findings indicated that congenital structural defects in some adult $A p j^{-1-}$ mice might further impair their cardiovascular function (14). Circulating and cardiac levels of apelin are reduced in patients with acute myocardial infarction and established coronary artery disease (15). Apelin-13 is considered to have the highest myocardial protective effect and significant therapeutic potential for end-stage heart failure (16).

It is thought that exercise training in morphinedependent patients may improve cardiac function by increasing the level of apelin. Beneficial effects of endurance, strength and concurrent training on left ventricular function have been demonstrated (14). However, it is not clear how these activities affect serum level of apelin in morphine-dependents. The present study aimed to investigate the effect of long-term aerobic, strength and concurrent exercise on circulating levels of apelin in morphine-dependent rats.

\section{MATERIAL AND METHODS}

This study was done on 50 male Wistar rats aged six weeks and weighting 150-180 g. The subjects were kept in a 12-hour light/dark cycle at stable room temperature $\left(22 \pm 1^{\circ} \mathrm{C}\right)$ and $55 \%$ relative humidity. The subjects had free access to food and tap water. Treatment protocols were designed in accordance with the National Institutes of Health Guide for the Care and Use of Laboratory Animals, and were later approved by the Institutional Animal Care and Use Committee at Hamedan University of Medical Sciences, Iran.

Prior to testing, the subjects were handled with care and their food intake and body weight were recorded on a daily basis. We added 0.1 $\mathrm{mg} / \mathrm{ml}$ (day 1-2), $0.2 \mathrm{mg} / \mathrm{ml}$ (day 3-4), 0.3 $\mathrm{mg} / \mathrm{ml}$ (day 5-6) and $0.4 \mathrm{mg} / \mathrm{ml}$ (day 7-21) of morphine to the drinking water provided for the subjects. In order to eliminate the bitter taste of morphine, $0.04 \mathrm{~g} / \mathrm{ml}$ sucrose was added to the drinking water (17). Naloxone (3 $\mathrm{mg} / \mathrm{Kg}$ body weight) was injected intraperitoneally to each rat in all experimental groups to examine morphine dependence. After confirmation of addiction in rats by the naloxone test, the subjects were randomly divided into four groups of sedentary- 
dependent rats (Sed-D, $\mathrm{N}=10$ ), endurance exercise-dependent rats (En-D, N=10), strength exercise-dependent rats $(\mathrm{St}-\mathrm{D}, \mathrm{N}=10)$ and concurrent exercise-dependent rats (Co-D, $\mathrm{N}=10$ ). In addition, 10 healthy rats (without addiction to morphine) were considered as the control group (Con, $\mathrm{N}=10$ ).

Endurance exercise: A motorized treadmill with eight individual lanes was used for aerobic exercise training program according to a protocol (18) including two periods of adaptation and exercise. Training started at speed of $10 \mathrm{~m} / \mathrm{min}$ walking and $5^{\circ}$ incline for 10 minute per session to adapt to exerciseinduced stress. If subjects remained stable, the speed and time were increased gradually to 30 $\mathrm{m} / \mathrm{min}$ and 60 minute per session at a $12^{\circ}$ incline for 10 weeks (5 days/week).

Resistance exercise: In this group, the rats underwent 10 weeks (5 days per week) of progressive resistance training. The subjects climbed a one-meter-high ladder with $85^{\circ}$ incline 12 times a day. Weights inside a cloth bag were tied to tail of the subjects with a band. The weights equaled $50 \%$ of the rat body weight and were gradually increased to $130 \%$ in 10 weeks (1st-2nd week: $50-60 \%$ of body weight; 3rd-5th week: $70-90 \%$ of body weight; 6th-8th week: 100-110\% of body weight, 9th-10th week: 110-130\% of body weight). Each training session consisted three set of four repetitions with a 3 minutes gap between sets and 15 seconds gap between trials. The exercise protocol used in our study was adopted from study of Philippe et al. with some modifications (19).

Concurrent exercise (combined resistanceaerobic training): In this group, subjects performed half of endurance and strength exercise sessions on the same day. This training group performed two set of three repetitions with 3 minutes gap between sets and 15 seconds gap between trials of ramp climbing, followed by 30 minutes of treadmill exercise at $30 \mathrm{~m} / \mathrm{min}$. The time and intensity were gradually increased and determined by the other two groups every week (20). No mortality was observed after the treatments. Blood samples $(3 \mathrm{ml})$ were taken from the animals' eye 48 hours after the last training session. After centrifugation at $10,000 \mathrm{rpm}$ for 10 minutes, serum samples were stored at -80 ${ }^{\circ} \mathrm{C}$ for the experiments. Apelin was measured by an ELISA Reader (ELX800, the USA) using an ELISA kit (Apelin ELISA kit, RAB0018, Sigma Aldrich- USA) according to the manufacturer's instructions.

Data were analyzed using SPSS (version 18). Normality of the data was confirmed by Shapiro-Wilk test. One-way analysis of variance was performed to evaluate differences between the groups. Post-hoc Tukey's test was used to determine the differences. Data are presented as mean \pm SEM and statistical significance level was set at 0.05 .

\section{RESULTS}

Serum levels of apelin were significantly different between the three groups $(\mathrm{F}=12.56, \mathrm{P}=$ 0.001). Moreover, serum levels of apelin increased significantly in morphine-dependent rats compared to healthy controls $(\mathrm{P}<0.05)$. The endurance and concurrent training significantly increased serum apelin levels in morphinedependent rats compared to addicted control group, but strength training had no effect on serum level of apelin ( Figure 1).

Figure 1- Circulating serum apelin in experimental groups (data are presented as mean \pm SEM)

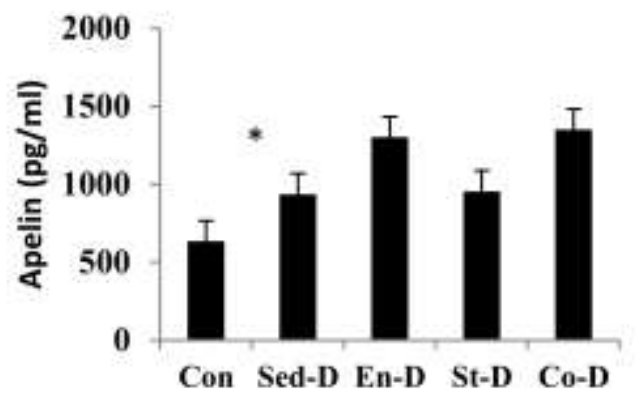

$*=\mathbf{P}<0.05$ VS Con group.

$\dagger=\mathbf{P}<0.05$ VS Con and Sed-D groups. 


\section{DISCUSSION}

Apelin is a multi-functional neuropeptide that plays an important role in energy homeostasis regulation, immune system, gastrointestinal function and cardiac function. Exercise can improve cardiac function in morphine-dependent patients. In our study, serum apelin increased in morphine-dependent rats compared to normal rats. The endurance and concurrent training had better effects on the cardiac function and increased serum apelin levels in morphine-dependent rats. Strength training did not affect the serum apelin level. These results confirm our hypothesis that exercise can improve cardiac function in morphine-dependent rats by increasing serum apelin level.

Physical exercise, diet and medications have been recommended as the mainstays of cardiovascular disease management. Regular endurance training can help prevent and/or treat several diseases (21). The cardioprotective benefits of physical exercise can be mediated by apelin. Aerobic exercise plays a beneficial role in ischemia reperfusion (22). However, its role in apelin regulation is controversial. Kadoglou et al. reported that aerobic exercise significantly upregulated apelin level (23). More recently, Krist et al. (24) and Sheibani et al. (7) found that exercise could decrease plasma apelin level and apelin mRNA expression. The cardioprotective effects of apelin have been reported by several studies (25-28). In this study, for the first time, we showed that morphine dependence increases the serum level of apelin. However, molecular mechanism of this increase is not clear. Considering the cardiac dysfunction in morphine-dependent patients, the body might increase the level of apelin as a protective mechanism to recover cardiac function.

We demonstrated that aerobic and concurrent training in morphine-dependent rats elevated

\section{REFERENCES}

1. Van Boekel LC, Brouwers EP, van Weeghel J, Garretsen HF. Public opinion on imposing restrictions to people with an alcohol-or drug addiction: a crosssectional survey. Social psychiatry and psychiatric epidemiology. 2013; 48(12): 2007-16. doi: 10.1007/s00127-013-0704-0.

2. Kleinz MJ, Baxter GF. Apelin reduces myocardial reperfusion injury independently of PI3K/Akt and P70S6 kinase. Regulatory peptides. 2008; 146(1): 271-7. serum apelin level. However, the reason for the exercise-induced increase in serum apelin levels is unclear. Zhang et al. demonstrated that aortic, myocardial, and plasma apelin concentrations increased by exercise training in hypertensive rats, which was accompanied by the elevation of the apelin mRNA expression level in aorta and heart (29). Therefore, aorta and cardiac tissues could be possible sources of the exercise-induced apelin elevation. Antioxidant enzymes, such as apelin, superoxide dismutase and catalase are essential for functioning of the cellular antioxidant defense system. These enzymes can prevent uncontrolled generation of reactive oxygen species by neutralizing highly reactive free radicals (30).

The exact mechanism through which training exercise increases plasma apelin is not clear. However, some studies have suggested HIF- $\alpha$, TNF- $\alpha$, insulin and training-induced mechanical stress as the main causes of increase in plasma apelin $(5,31)$.

\section{CONCLUSION}

The findings of this study show that morphine dependence significantly increases serum apelin level. On the other hand, endurance and concurrent training unlike strength training significantly elevate serum apelin level.

\section{ACKNOWLEDGMENTS}

This study was funded by the Department of Research and Technology of Bu-Ali Sina University. The authors would like to express their gratitude to the staff of Neurophysiology Research Center Hamadan University of Medical Sciences for their support.

\section{CONFLICT OF INTEREST}

The authors declare that there is no conflict of interest.

3. Mesripour A, Iyer A, Brown L. Mineralocorticoid Receptors Mediate Cardiac Remodelling in MorphineDependent Rats. Basic \& clinical pharmacology \& toxicology. 2012; 111(2): 75-80. doi: 10.1111/j.17427843.2012.00860.x.

4. Kleinz MJ, Davenport AP. Emerging roles of apelin in biology and medicine. Pharmacology \& therapeutics. 2005; 107(2): 198-211. 
5. Fujie S, Sato K, Miyamoto-Mikami E, Hasegawa N, Fujita S, Sanada K, et al. Reduction of Arterial Stiffness by Exercise Training Is Associated with Increasing Plasma Apelin Level in Middle-Aged and Older Adults. PloS one. 2014; 9(4): e93545. doi: 10.1371/journal.pone.0093545.

6. Przewlocka-Kosmala M, Kotwica T, Mysiak A, Kosmala W. Reduced circulating apelin in essential hypertension and its association with cardiac dysfunction. Journal of hypertension. 2011;29(5):971-9. doi: 10.1097/HJH.0b013e328344da76.

7. Sheibani S, Hanachi P, Refahiat MA. Effect of aerobic exercise on serum concentration of apelin, TNFa and insulin in obese women. Iranian journal of basic medical sciences. 2012; 15(6): 1196-1201.

8. Foussal C, Lairez O, Calise D, Pathak A, GuilbeauFrugier C, Valet P, et al. Activation of catalase by apelin prevents oxidative stress-linked cardiac hypertrophy. FEBS letters. 2010; 584(11): 2363-70. doi: 10.1016/j.febslet.2010.04.025.

9. Wang W, McKinnie SM, Patel VB, Haddad G, Wang $\mathrm{Z}$, Zhabyeyev $\mathrm{P}$, et al. Loss of Apelin exacerbates myocardial infarction adverse remodeling and ischemiareperfusion injury: therapeutic potential of synthetic Apelin analogues. Journal of the American Heart Association. 2013;2(4):e000249. doi: 10.1161/JAHA.113.000249.

10. Gross ER, Hsu AK, Gross GJ. The JAK/STAT pathway is essential for opioid-induced cardioprotection: $J A K 2$ as a mediator of STAT3, Akt, and GSK-3 $\beta$. American Journal of Physiology-Heart and Circulatory Physiology. 2006; 291(2): H827-H34.

11. Kuba K, Zhang L, Imai Y, Arab S, Chen M, Maekawa Y, et al. Impaired heart contractility in Apelin gene-deficient mice associated with aging and pressure overload. Circulation research. 2007; 101(4): e32-e42.

12. Charo DN, Ho M, Fajardo G, Kawana M, Kundu RK, Sheikh AY, et al. Endogenous regulation of cardiovascular function by apelin-APJ. American Journal of Physiology-Heart and Circulatory Physiology. 2009; 297(5): H1904-H13. doi: 10.1152/ajpheart.00686.2009.

13. Kawamata Y, Habata Y, Fukusumi S, Hosoya M, Fujii R, Hinuma S, et al. Molecular properties of apelin: tissue distribution and receptor binding. Biochimica et Biophysica Acta (BBA)-Molecular Cell Research. 2001; 1538(2): 162-71.

14. Kang Y, Kim J, Anderson JP, Wu J, Gleim SR, Kundu RK, et al. Apelin-APJ signaling is a critical regulator of endothelial MEF2 activation in cardiovascular development. Circulation research. 2013; 113(1): 22-31. doi: 10.1161/CIRCRESAHA.113.301324.

15. Boal F, Roumegoux J, Alfarano C, Timotin A, Calise $\mathrm{D}$, Anesia R, et al. Apelin regulates FoxO3 translocation to mediate cardioprotective responses to myocardial injury and obesity. Scientific reports. 2015; 5: 16104. doi: 10.1038/srep16104.

16. Yang S, Li H, Tang L, Ge G, Ma J, Qiao Z, et al. Apelin-13 protects the heart against ischemia-

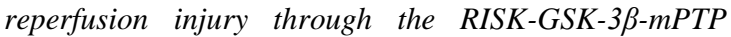
pathway. Archives of medical science: AMS. 2015; 11(5):1065. doi: 10.5114/aoms.2015.54863.
17. BADAWY AB, Evans C, Evans M. Production of tolerance and physical dependence in the rat by simple administration of morphine in drinking water. British journal of pharmacology. 1982; 75(3): 485-91. DOI: 10.1111/j.1476-5381.1982.tb09165.x..

18. Ranjbar K, Nazem F, Nazari A. Effect of exercise training and L-arginine on oxidative stress and left ventricular function in the post-ischemic failing rat heart. Cardiovasc Toxicol. 2016; 16(2): 122-9. doi: 10.1007/s12012-015-9319-x.

19. Philippe AG, Py G, Favier FB, Sanchez AM, Bonnieu A, Busso T, et al. Modeling the responses to resistance training in an animal experiment study. BioMed research international. 2015; 2015. DOI: $10.1155 / 2015 / 914860$

20. Rech A, Radaelli R, De Assis AM, Fernandes JR, Longoni A, Vozari-Hampe MM, et al. The effects of strength, aerobic, and concurrent exercise on skeletal muscle damage in rats. Muscle \& nerve. 2014; 50(1): 7986. doi: 10.1002/mus.24091.

21. Ashrafi J, Roshan VD. Is short-term exercise a therapeutic tool for improvement of cardioprotection against DOX-induced cardiotoxicity? An experimental controlled protocol in rats. Asian Pacific Journal of Cancer Prevention. 2012; 13(8): 4025-30.

22. Sigal RJ, Kenny GP, Wasserman DH, CastanedaSceppa C, White RD. Physical activity/exercise and Type 2 diabetes A consensus statement from the American Diabetes Association. Diabetes care. 2006; 29(6): 14338

23. Kadoglou NP, Vrabas IS, Kapelouzou A, Lampropoulos S, Sailer N, Kostakis A, et al. The impact of aerobic exercise training on novel adipokines, apelin and ghrelin, in patients with type 2 diabetes. Medical Science Monitor Basic Research. 2012; 18(5): CR290CR5.

24. Krist J, Wieder K, Klöting N, Oberbach A, Kralisch $\mathrm{S}$, Wiesner $\mathrm{T}$, et al. Effects of weight loss and exercise on apelin serum concentrations and adipose tissue expression in human obesity. Obesity facts. 2013; 6(1): 57-69. DOI:10.1159/000348667.

25. Szokodi I, Tavi P, Földes G, Voutilainen-Myllylä S, Ilves M, Tokola H, et al. Apelin, the novel endogenous ligand of the orphan receptor APJ, regulates cardiac contractility. Circulation research. 2002; 91(5): 434-40.

26. Ashley EA, Powers J, Chen M, Kundu R, Finsterbach $\mathrm{T}$, Caffarelli A, et al. The endogenous peptide apelin potently improves cardiac contractility and reduces cardiac loading in vivo. Cardiovascular research. 2005;65(1):73-82.

27. Berry MF, Pirolli TJ, Jayasankar V, Burdick J, Morine KJ, Gardner TJ, et al. Apelin has in vivo inotropic effects on normal and failing hearts. Circulation. 2004;110(11 suppl 1): II-187-II-93.

28. Scott IC, Masri B, D'Amico LA, Jin S-W, Jungblut $\mathrm{B}$, Wehman $\mathrm{AM}$, et al. The g protein-coupled receptor agtrl1b regulates early development of myocardial progenitors. Developmental cell. 2007; 12(3): 403-13.

29. Zhang J, Ren CX, Qi YF, Lou LX, Chen L, Zhang $\mathrm{LK}$, et al. Exercise training promotes expression of apelin and APJ of cardiovascular tissues in spontaneously hypertensive rats. Life sciences. 2006; 79(12): 1153-9. 
32/ Effect of 8-Week Aerobic. ..

30. Mates J. Effects of antioxidant enzymes in the molecular control of reactive oxygen species toxicology. Toxicology. 2000;153(1):83-104.
31. Andersen CU, Hilberg O, Mellemkjær S, NielsenKudsk JE, Simonsen U. Apelin and pulmonary hypertension. Pulmonary circulation. 2011; 1(3): 334. doi: $10.4103 / 2045-8932.87299$. 